\title{
曲線路の障害物回避ドライバモデルに関する研究*
}

$$
\begin{array}{lllll}
\text { 原 田 正 範*1, 永 友 恒 } \text { 知 }^{* 2} \\
\text { 三 谷 } \text { 仁 宏*2, 吉 本 堅 }{ }^{* 1}
\end{array}
$$

\section{Driver Models for a Vehicle Avoidance Maneuver in Cornering}

\author{
Masanori HARADA*3, Tsunenori NAGATOMO, \\ Yoshihiro MITANI and Kenichi YOSHIMOTO \\ ${ }^{* 3}$ Department of Mechanical Engineering, National Defense Academy in Japan, \\ 1-10-20 Hashirimizu, Yokosuka-shi, Kanagawa, 239-8686 Japan
}

\begin{abstract}
This paper presents driver models for a vehicle avoidance maneuver in cornering. The models are based on a preview driver model which has either a compensation control or a pursuit control. The preview point is detected by a variation of the present radius which is equivalent to a third-order prediction model, including a centrifugal jerk. The unknown control gains in the models are determined by an optimization program based on a Legendre pseudospectral method. A secondorder prediction model, commonly used in cornering analysis, is compared to numerical examples. For the compensation model, the Proportional-Integral (PI) control results in a steering angle with two distinct behavior clearly: 1) steady-state cornering due to the Integral (I) control and 2) transient response due to the Proportional ( P) control. The pursuit control has a sufficient response when the steering angle for the steady-state cornering is provided via feed-forward control, even if the $\mathrm{P}$ control is used for the compensator.
\end{abstract}

Key Words : Automobile, Optimal Control, Human Engineering, Preview Driver Model, Avoidance Maneuver, Cornering

\section{1. 序}

交通事故の形態は様々であり，曲線路における事故 もその一例である．曲線路における事故は，速度超過 や障害物回避操作に起因する車線逸脱などがあり，車 両運動の解析により事故発生のメカニズムを把握する ことは重要である．曲線路走行に関する車両運動の研 究の多くは, 定常状態での偏差の低減と安定性の向上 を目的としている．また，障害物回避に関する研究の 多くは, 直線路における解析である. しかしながら， ドライバの障害物回避操作は曲線路においても発生す るため,これらを組み合わせた解析が必要である.こ のためには, 複雑なドライバの操作を, 数学的にモデ ル化したドライバモデルの構築が重要となる.

前方誤差修正モテルは, ドライバが現在の車両状態 を基に車両が将来到達する位置の予測を行い, 予測位 置と目標コースとの誤差が無くなる様に操舵を行うモ デルである．将来位置の予測方法は，直線状に予測を 行う一次予測モテルや ${ }^{(1)}$, 曲率に沿った予測を行う二

* 原稿受付 2005 年 5 月 25 日.

*1 正員, 防衛大学校システム工学群機械工学科(王239-8686 横須賀市走水 1-10-20).

*2 防衛大学校研究科.

E-mail : mharada@nda.ac.jp
次予測モデル゙ある(2)。これらの予測モデルでは, 得 られた誤差が小さくなる様に, 比例制御 $(\mathrm{P}$ 制御) や 積分制御 (I 制御) などの演算を行って必要な操舵角を 得ている.

曲線路解析で有用な二次予測モデルは, 現在の速度 と加速度が保持されると仮定されている. しかし，二 次予測と積分制御を組み合わせた吉本モデルでは，障 害物回避などの急激な操舵は表現できない( ${ }^{(3)}$. 一方, 人間の腕の操作等では移動時の躍度の情報を感知して いるという研究があり ${ }^{(4)}$ ，また障害物回避における目 標コース設定において躍度が最小になる目標軌道をド ライバが選択すると仮定している研究がある(5).

そこで本研究では, ドライバが躍度を感知でき，操 釈に用いることができると仮定して，躍度まで考慮し た三次予測モデルを提案する ${ }^{(6)}$. この三次予測による 将来偏差に対するフィードバック制御とフィードフォ ワード制御を組み合わせた操舵モテルと, 従来の二次 予測を用いた操舵モデルの曲線路の障害物回避の比較 を行い，三次予測の有効性を検証する. 


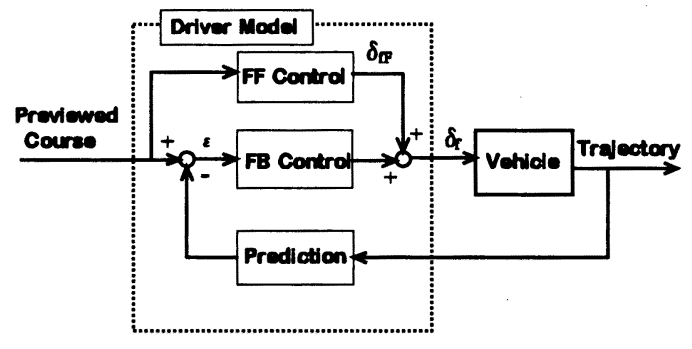

Fig. 1 Driver-vehicle system

\section{2. ドライバ-自動車系の定式化}

ドライバ-自動車系の概念を図 1 に示す. ドライバ は, 目標コースと車両運動で得た情報により, 予測部 と操舵部で車両に入力をする操舵角の演算を行う. 予 測部では, 現在の車両状態を用いて将来の車両位置の 予測を行う．操舵部には, 目標コースの情報を用いて あらかじめ操舵を行う FF（フィードフォワード）操 舵部と, 走行誤差を修正する FB（フィードバック）操 舵部がある。

$2 \cdot 1$ 車両の運動方程式車両の運動方程式は, 図 2 に示される等価二輪モデルを用いると式 (1) (5) で表される．座標系や記号の定義は図 $2 ， 3$ に示す通 りである.

$$
\begin{aligned}
m(\dot{v}+u r) & =S_{f}+S_{r} \\
I_{z} \dot{r} & =a S_{f}-b S_{r} \\
\dot{\psi} & =r \\
\dot{x} & =u \cos \psi-v \sin \psi \\
\dot{y} & =u \sin \psi+v \cos \psi
\end{aligned}
$$

ここで, $m$ は車両の質量, $I_{z}$ はヨー軸まわりの慣性 モーメントである. タイヤが発生する横力 $S_{f}, S_{r}$ は, タイヤの横滑り角の変化に対して飽和しない領域では 式 (6), (7) で表される. 本研究では, 障害物回避は八 ンドルにより行われると仮定し, 走行速度 $u$ は変化し ないとする.

$$
\begin{aligned}
& S_{f}=C_{f}\left(\delta_{f}-\frac{v+a r}{u}\right) \\
& S_{r}=C_{r}\left(-\frac{v-b r}{u}\right)
\end{aligned}
$$

2.2 予測部 曲線路を走行中のドライバは, 図 3 の様にコースに治った予測を行うと考えられる. 曲 線路を円弧と仮定し, 円の中心と座標系の原点を一致 させ, 現在の車両位置 $\left(x_{0}, y_{0}\right)$ とすると, $T_{p}$ 秒後の 車両位置 $\left(x_{p}, y_{p}\right)$ は式 $(8)$, (9) で表される. 従来の 研究では, 車両の現在位置における速度と加速度が保

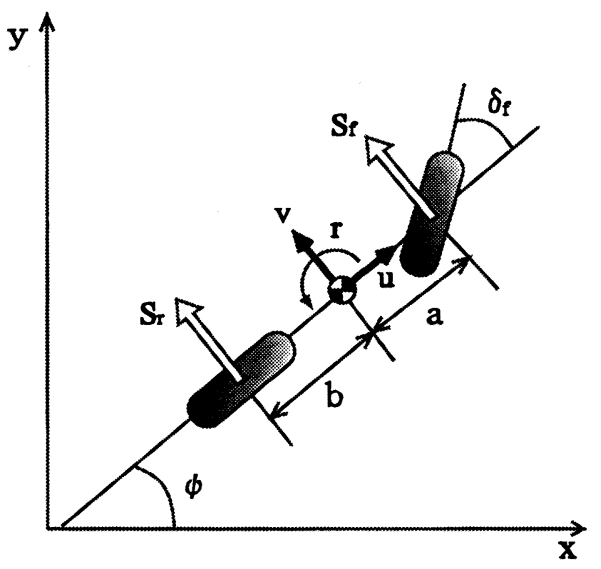

Fig. 2 Equivalent bicycle model

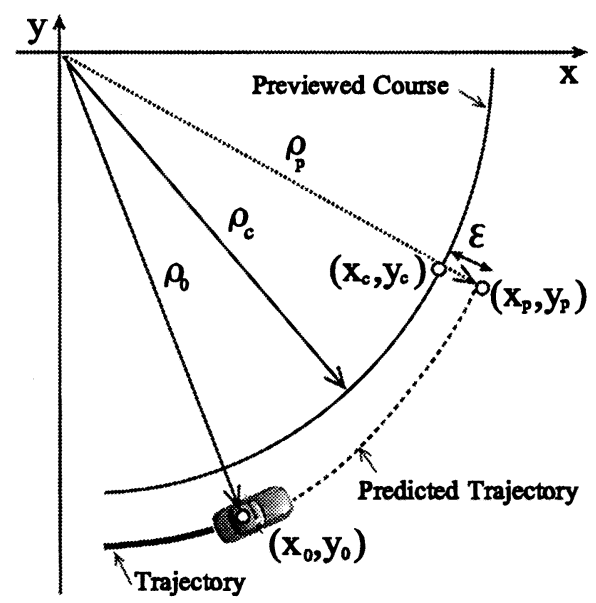

Fig. 3 Preview model in cornering

持されると仮定して，2 階微分項までを考慮した二次 予測 ${ }^{(2)}$ が用いられている.

$$
\begin{aligned}
& x_{p}=x_{0}+\dot{x}_{0} T_{p}+\frac{1}{2} \ddot{x}_{0} T_{p}^{2}+\frac{1}{6} \dddot{x}_{0} T_{p}^{3} \cdots \\
& y_{p}=y_{0}+\dot{y}_{0} T_{p}+\frac{1}{2} \ddot{y}_{0} T_{p}^{2}+\frac{1}{6} \dddot{y}_{0} T_{p}^{3} \cdots
\end{aligned}
$$

ここで提案しているドライバモデルは横方向の躍度 を感知できると仮定しているので，3 階微分項までを 含めた式 (8), (9) になり, 数值計算の負担が増加する. そこで, 一定の曲率半径 $\rho_{0}$ と，その変化を考慮した 式 (10) を, 新たな三次予測モデルとして提案する.

$$
\rho_{p}=\rho_{0}+\dot{\rho}_{0} T_{p}
$$

二次予測は, 現在位置での曲率半径 $\rho_{0}$ と, $T_{p}$ 秒後 の予測位置における曲率半径 $\rho_{p}$ が等しくなる予測で ある.これに対して式 (10) は, 3 階微分項が曲率変化 
$\dot{\rho}_{0} T_{p}$ に相当し, 速度や加速度に加えて, 躍度が保持 されると仮定した三次予測である. 旋回中は $\rho_{0} \neq 0$ であり, $\rho_{0}, \dot{\rho}_{0}$ は式 (11), (12) で与えられる.

$$
\begin{aligned}
& \rho_{0}=\sqrt{x_{0}^{2}+y_{0}^{2}} \\
& \dot{\rho}_{0}=\frac{x_{0} \dot{x}_{0}+y_{0} \dot{y}_{0}}{\rho_{0}}
\end{aligned}
$$

$2 \cdot 3$ 操舵部操舵部は, 以下の補償制御と追跡 制御の二種類を考える.

(1) 補償制御： FB 操舵部のみ

(2) 追跡制御 : FF 操舵部之 FB 操舵部

$\mathrm{FB}$ 操舵部は, 予測部で得られた曲率半径 $\rho_{p}$ と目標 コース $\rho_{c}$ の差 $\epsilon$ に対して, P 制御もしくは PI 制御を 行うものとする. FF 操舵部は, 一定の速度と曲率半 径の定常円旋回に必要な操舵角を与える. また, FB 操舵部には機械的および生理的な時定数 $T_{s}$ 秒の一次 遅れを考虑する.

2.3.1 FB 操舵部による補倓制御 目標コース との誤差を $\epsilon$ とすると, $\mathrm{P}$ 制御による操舵角 $\delta_{f P}$ は式 (13), I 制御による操舵角 $\delta_{f I}$ は式 (14) となる.

$$
\begin{gathered}
\delta_{f P}=G_{p} \frac{1}{T_{s} s+1} \epsilon \\
\delta_{f I}=\frac{G i}{s} \frac{1}{T_{s} s+1} \epsilon
\end{gathered}
$$

二次予測による定常円旋回では, $\mathrm{P}$ 制御を行うと定 常偏差を生じるため, I 制御による補償が必要となる ことが知られている. 提案する三次予測では, 式 (15) に定常旋回の条件 $\dot{\delta}_{f P}=0=\dot{\rho}$ を考慮すると式 (16) が得られる.これは目標コースと現在位置が一致する 場合は操舵角が得られず, 目標コース上の定常円旋回 が不可能であり, 必要な操舵角を得るためには, 定常 偏差が発生することを示している.

$$
\begin{aligned}
T_{s} \dot{\delta}_{f P}+\delta_{f P} & =G_{p}\left(\rho_{0}+\dot{\rho_{0}} T_{p}-\rho_{c}\right) \\
\delta_{f P} & =G_{p}\left(\rho_{0}-\rho_{c}\right)
\end{aligned}
$$

定常偏差の補償のためには I 制御が有効であるが, 障害物回避の応答性まで考慮する場合は $\mathrm{P}$ 制御を含め る必要がある. そこで式 (17) の PI 制御操舵角 $\delta_{f P I}$ を考える.

$$
\begin{aligned}
\delta_{f P I} & =\delta_{f P}+\delta_{f I} \\
& =\frac{s G_{p}+G i}{s} \frac{1}{T_{s} s+1} \epsilon
\end{aligned}
$$

式 (17) より式 (18) が与えられ, 定常円旋回時は $\delta_{f P I}, \rho_{0}, \epsilon$ は変化しないので式 (19) が得られる.こ れは定常偏差が生じないことを示している.

$$
\begin{aligned}
T_{s} \ddot{\delta}_{f P I}+\dot{\delta}_{f P I} & =G_{p} \dot{\epsilon}+G_{i}\left(\rho_{0}+\dot{\rho}_{0} T_{p}-\rho_{c}\right) \\
0 & =G_{i}\left(\rho_{0}-\rho_{c}\right)
\end{aligned}
$$

以上より, 補償制御の解析を行う場合は, $\mathrm{P}$ 制御で は $\delta_{f}=\delta_{f P}, \mathrm{PI}$ 制御では $\delta_{f}=\delta_{f P I}$ とする.

$\mathbf{2 \cdot 3 \cdot 2}$ 追跡制御 ドライバは, 曲線路走行にお いては走行速度, 曲率半径, 運転経験などの情報に基 いて, FF 制御により曲線路走行に必要な操舵をあら かじめ行い, 走行誤差を FB 制御で補償していると考 えられる. そこで, $\delta_{f}$ を FF 操舵部の操舵角 $\delta_{f F}$ と $\mathrm{FB}$ 操舵部の操舵角 $\delta_{f B}$ を組み合わせた, 式 (20) で与 えられる追跡制御を考える.

$$
\delta_{f}=\delta_{f F}+\delta_{f B}
$$

$\delta_{f F}$ の值は, 目標コースの曲率半径を, 一定速度に より定常円旋回を行うために必要な操舵角を考える. これは定常円旋回の釣り合い条件 $\dot{v}=0=\dot{r}$ を式 (1), (2) に代入する事で与えられる一定值である. $\delta_{f B}$ は FB 操舵部より与えられ, $\mathrm{P}$ 制御操舵角 $\delta_{f P}$ もしくは $\mathrm{PI}$ 制御操舵角 $\delta_{f P I}$ による誤差の修正制御を考える.

2.4 パラメタ最適化法による㟫舵ゲインの探索 設定した走行条件における操蛇ゲイン $G_{p}, G_{i}$ の值 は, パラメタ最適化手法により探索を行う. 状態変数 を $\boldsymbol{X}(t)$, 未知のパラメタを $\Pi$ とすると, パラメ夕最 適化問題は式 $(21) \sim(24)$ で表される.

$$
\begin{aligned}
\text { Minimize } & J(\boldsymbol{X}(t), \Pi) \\
\dot{\boldsymbol{X}}(t)= & \boldsymbol{f}(\boldsymbol{X}(t), \Pi) \\
\boldsymbol{X}\left(t_{0}\right)= & \boldsymbol{X}_{0} \\
\boldsymbol{g}(\boldsymbol{X}(t), \Pi) \leq & 0
\end{aligned}
$$

式 (21) は評価関数, 式 (22) は式 (1) (5) の運動方程 式と操舵角 $\delta_{f}$ に関する状態方程式, 式 (23) は状態量 の初期条件, 式 (24) は拘束条件である. 本研究の解 析では, $\boldsymbol{X}, \Pi$ は以下のとおりである.

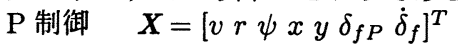

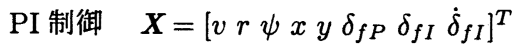

また П は以下の様になる.

$\mathrm{P}$ 制御 : $\quad \Pi=\left[G_{p}\right]$

$\mathrm{PI}$ 制御 : $\quad \Pi=\left[G_{p} G_{i}\right]^{T}$

評価関数は, 目標コースと現在位置の誤差 $\rho_{0}-\rho_{c}$, 操 舵角速度 $\dot{\delta}_{f}$ を用いて式 (25) で定義する.

$$
J=\frac{1}{t_{f}} \int_{0}^{t_{f}}\left\{q_{1}\left(\rho_{0}-\rho_{c}\right)^{2}+q_{2} \dot{\delta}_{f}^{2}\right\} d t
$$

定式化した最適化問題は非線形であるため, 反復計 算により解を得る必要がある. そこで, 状態変数を含 む非線形最適化問題の最適パラメタの探索は, 擬スペ クトル法を用いた離散化により非線形計画問題に変換 して最適化を行うソフトウエア ${ }^{(7)}{ }^{(8)}$ を用いた. 


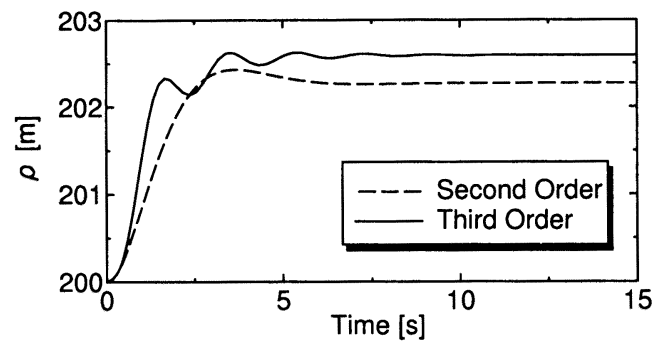

(a) Transient response for radius

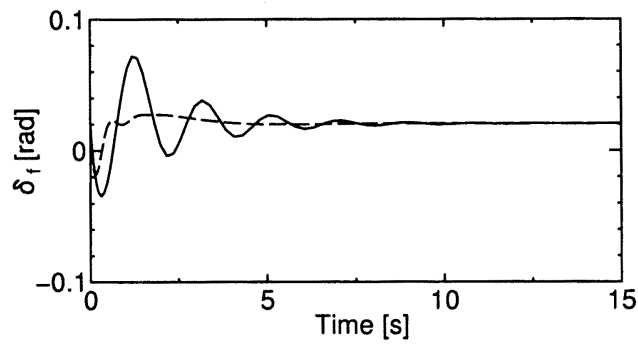

(b) Transient response for steering angle

Fig. 4 Transient response for $\mathrm{P}$ control of compensation control

Table 1 Results for $\mathrm{P}$ control of compensation control

\begin{tabular}{|l|c|c|}
\hline & $G_{p}$ & $J$ \\
\hline Second Order & 0.0738 & 0.0045 \\
\hline Third Order & 0.0344 & 0.0074 \\
\hline
\end{tabular}

\section{3. 曲線路走行のドライバモデルの数值解析}

半径 $200[\mathrm{~m}]$ の定常円旋回中の車両が, 障害物を視 認して外側へ $2[\mathrm{~m}]$ のレーンチェンジによる障害物回 避運動を行う場面を想定する. シミュレーション時間 を $t_{f}=15[\mathrm{~s}]$, 走行速度を $u=20[\mathrm{~m} / \mathrm{s}]$, 操舵遅れを $T_{s}=0.2[\mathrm{~s}]$, 各状態量の初期条件は, 障害物回避前の 定常円旋回時の值に設定する. 最適化するパラメタが 多くなると, 各パラメ夕の影響を把握する事が困難と なるため, 本研究では原田 ${ }^{(9)}$ の解析を参考にして予測 時間を $T_{p}=1.6[\mathrm{~s}]$ に固定した. また最適化する操舵 ゲイン $G_{p}, G_{i}$ は時間変化しないとする. 車両の諸元 は国産中型車のものを用いた ${ }^{(10)}$. 最適化計算の際の 各変数は無次元化されており, 式 (25) の評価関数值 における重みは, 無次元化量に対して $q_{1}=1, q_{2}=1$ とする. 以上の設定に対して，予測部を従来の二次予 測と, 提案する三次予測の場合について比較を行う.

3.1 FB 制御のみによる障害物回避 FB 操舵部 を $\mathrm{P}$ 制御とした時の, 曲率半径と操舵角の時間応答を

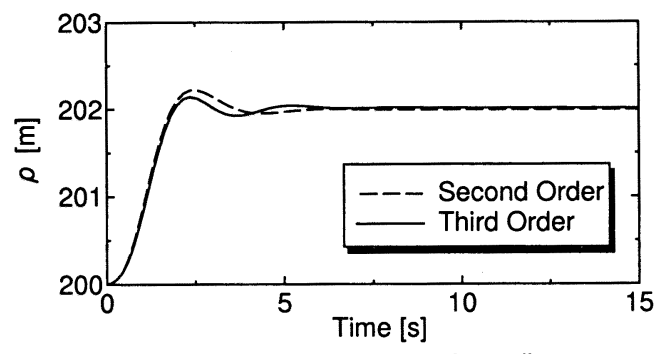

(a) Transient response for radius

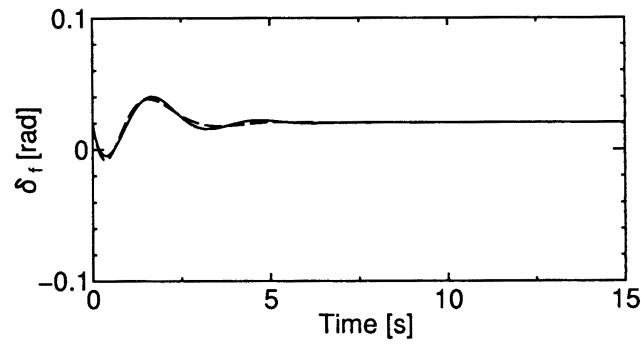

(b) Transient response for steering angle

Fig. 5 Transient response for PI control of compensation control

Table 2 Results for PI control of compensation control

\begin{tabular}{|l|c|c|c|}
\hline & $G_{p}$ & $G_{i}$ & $J$ \\
\hline Second Order & 0.0117 & 0.0435 & 0.0028 \\
\hline Third Order & 0.0185 & 0.0011 & 0.0028 \\
\hline
\end{tabular}

図 4 に示し，表 1 に操舵ゲインの值と評価関数值を示 す. 二次予測と三次予測のどちらの場合も, 定常偏差 が生じている事が示されている. 三次予測は二次予測 よりも操舵ゲインが低いが, 応答が振動的でありまた 定常偏差が大きくなっている，このため評価関数の值 も高くなっている.

$\mathrm{P}$ 制御の場合は二次予測と三次予測いずれの場合も 定常偏差が生じるので，これを補償するために FB 操 舵部に PI 制御を適用する. 図 5 に, 曲率半径と操舵 角の時間応答を示し, 表 2 に得られたゲインの值と評 価関数值を示す．二次予測と三次予測のどちらの場合 も，定常偏差が無くなり目標コースに追従し，応答性 も同じ様になっている.

$\mathrm{PI}$ 制御は, $\mathrm{P}$ 制御操舵角 $\delta_{f P}$ と I 制御操舵角 $\delta_{f I}$ の 和であるため, それぞれの操舵角が, 全体の操舵角に 与える影響を検討する必要がある。図 6 に，P制御と I 制御の操舵角の時間応答を示す，二次予測では，過 渡応答の際に P 制御と I 制御とも操舵角が変化する 


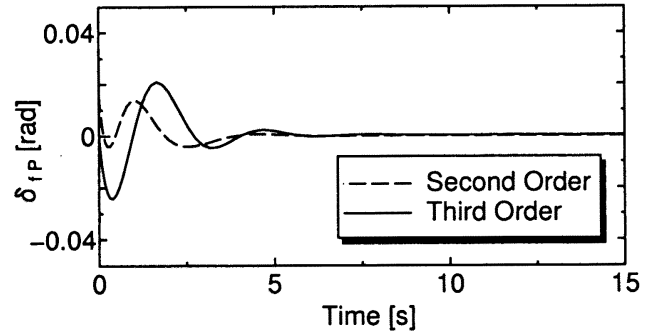

(a) Transient response for $\mathrm{P}$ control steering angle

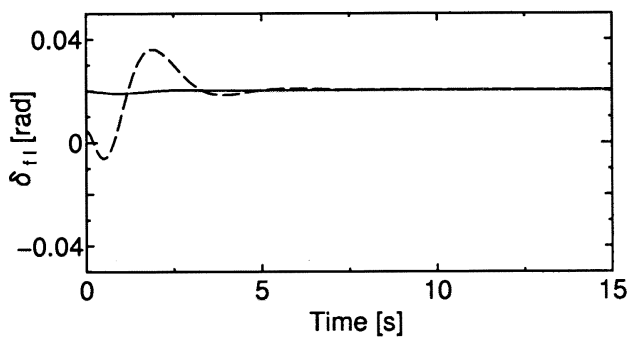

(b) Transient response for I control steering angle

Fig. 6 Detail for PI control steering angle

が，三次予測では I 制御の操舵角は定常円旋回時の操 觗角を保持してほぼ一定であり, 過渡応答の制御は $\mathrm{P}$ 制御が行っている事が示されている. したがたって, 車両に入力される操舵角は同じであっても, 操舵部の 内部で演算される操舵角には予測モデルにより違いが ある事がわかる.

3.2 FF 制御を付加した場合の障害物回避補 償制御の場合で示された様に, 三次予測モデルの I 制 御操舵角は定常円旋回時の操舵角を保持していた. そ こで, I 制御で得ていた目標コースの定常円旋回に必 要な操舵角を $\mathrm{FF}$ 操舵部で与え, $\mathrm{FB}$ 操舵部を $\mathrm{P}$ 制御 もしくは PI 制御として誤差を補償する追跡制御が有 効であると考えられる.

図 7 に, FB 操舵部を $\mathrm{P}$ 制御とした場合の曲率半径 と操舵角の時間応答を示し, 表 3 に操舵ゲインの值と 評価関数值を示す. 定常偏差は二次予測と三次予測と も発生していないが, 三次予測の方が収束性がよく, 操舵ゲインが小さい值となっている. また評価関数值 も小さくなっている.

図 8 に, FB 操舵部を PI 制御とした場合の曲率半径 と操舵角の時間応答を示し, 表 4 に操舵ゲインの值と 評価関数值を示す. また図 9 に, この場合の $\mathrm{P}$ 制御操 舵角と I 制御操舵角を示す. 二次予測は $\mathrm{P}$ 制御の場合 に対して応答性が変化して応答性が改善され，評価関 数值も改善している.この際，補償制御の場合と同

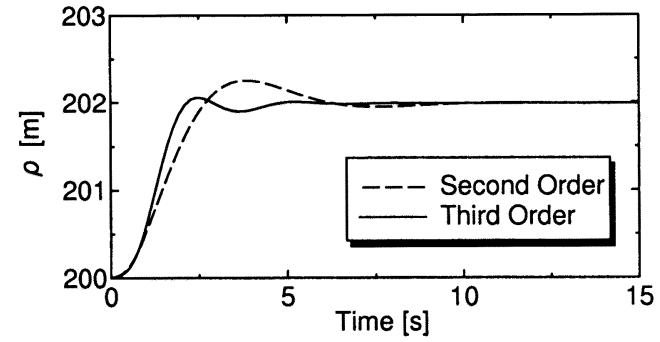

(a) Transient response for radius

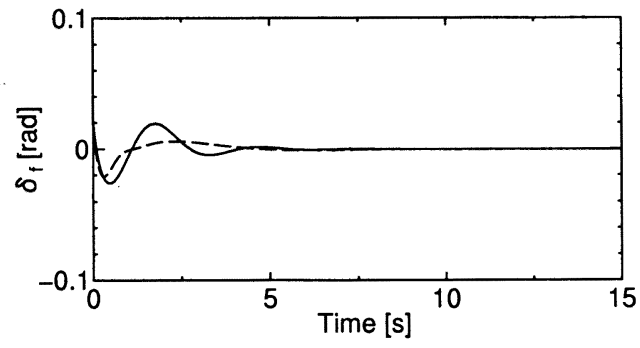

(b) Transient response for steering angle

Fig. 7 Transient response for $\mathrm{P}$ control of pursuit control

様にI 制御操舵角が変化している事が示されている.

Table 3 Results for $\mathrm{P}$ control of pursuit control

\begin{tabular}{|l|c|c|}
\hline & $G_{p}$ & $J$ \\
\hline Second Order & 0.0245 & 0.0038 \\
\hline Third Order & 0.0189 & 0.0034 \\
\hline
\end{tabular}

これに対して, 三次予測は $\mathrm{P}$ 制御の場合に対して変化 はせず，評価関数值の值も同じとなっており，また I 制御操觤角はゼロとなっている事が示されている.

以上の結果より，追跡制御では，二次予測は PI 制 御まで考える必要があるが, 三次予測は $\mathrm{P}$ 制御でも有 効であることが示されている. また, $\mathrm{P}$ 制御を用いた 解析は, 運動方程式中の状態量の次数が PI 制御に比 べて低くなり，さらに設定する操蛇ゲインが $G_{p}$ のみ で解析が容易となる.

\section{4. 結 論}

曲線路における障害物回避を行うドライバモテルと して, 躍度を考慮した三次予測モデルを提案し, 数值 計算により従来の二次予測モテルと比較して, 次の結 果を得た.

1) フィードバック制御のみの操舵モデルでは, 二次 予測モデルおよび三次予測モテルとも PI 制御が必要 で，性能はほぼ同等である.

2) フィードフォワード制御を付加する操舵モテルで 


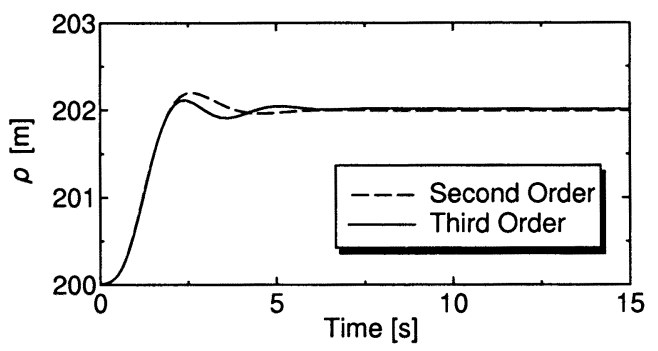

(a) Transient response for radius

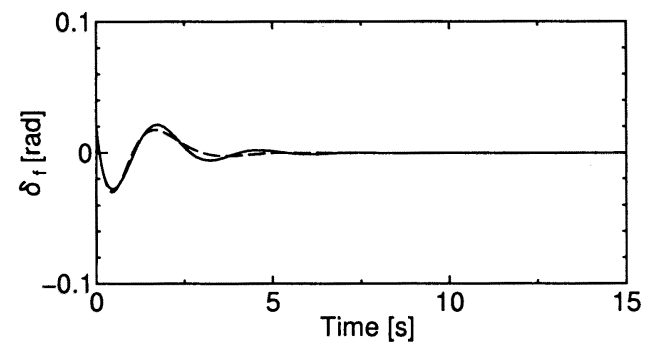

(b) Transient response for steering angle

Fig. 8 Transient Response for PI control of pusuit control

Table 4 Results for PI control of pursuit control

\begin{tabular}{|l|c|c|c|}
\hline & $G_{p}$ & $G_{i}$ & $J$ \\
\hline Second Order & 0.0121 & 0.0451 & 0.0034 \\
\hline Third Order & 0.0196 & 0.0012 & 0.0034 \\
\hline
\end{tabular}

は, 二次予測モデルでは PI 制御が必要であるが, 三次 予測モテルでは $\mathrm{P}$ 制御のみで十分な性能が得られる.

以上より，提案する三次予測モデルは設定すべきパ ラメタが少なくなり, 曲線路における障害物回避の解 析用ドライバモデルとして有用であることが示された.

\section{文献}

(1) Kondo,M., Fundamental Relation between the Steering and the Behavior of Automobile, Jidosha Gijutsukai Ronbunshu(Transactions of the Society of Automotive Engineers of Japan),5(1958),40-43.

(2) Yoshimoto,K., Simulation of Man-Automobile Systems by the Driver's Steering Model with Predictability, Bulletin of the Japan Society of Mechanical Engineers,12-51(1969),495-500.

(3) Nagatomo,T.,Harada,M.,and Yoshimoto,K., Avoidance Behavior of a Cornering Vehicle, Kotsu Butsuryu Bumon Taikai Koen Ronbunshu 10(Proceedings of 10th Transportation and Logistics Conference),(2001),193-196.

(4) Itoh,K.,and M.Itoh, Motion Control in Biological Body and Robot, (1991),190, The 30th Anniversary

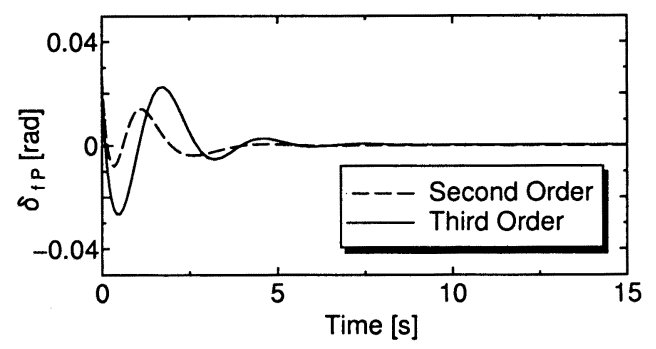

(a) Transient response for $\mathrm{P}$ control steering angle

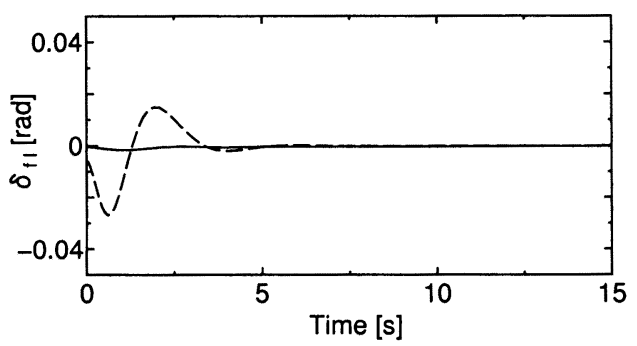

(b) Transient response for I control steering angle

Fig. 9 Detail for PI control steering angle

Publication of the Japan Society of Instrument and Control Engineers(CORONA PUBLISHING).

(5) Amano,Y.,Hada,M.,and Doi,S., Model of Driver's Behavior in Ordinary and Emergent Situations, RED Review of Toyota CRDL,33-1(1998),23-30.

(6) Mitani,Y.,Harada,M.,and Yoshimoto,K., Avoidance Behavior Including Speed Control of a Cornering Vehicle, Kotsu Butsuryu Bumon Taikai Koen Ronbunshu 12(Proceedings of 12th Transportation and Logistics Conference),(2003),107-110.

(7) Fahroo,F., and Ross,I.M., Costate Estimation by a Legendre Pseudospectral Method, Journal of Guidance, Control, and Dynamics,24-2(2001),270277.

(8) Ross,I.M., User's Manual for DIDO 2003 : A MATLAB Application Package for Dynamic Optimization, Department of Mechanical and Astronautical Engineering, NPS Technical Report ( Naval Postgraduate School ), MAE-03-005(2003).

(9) Harada,H., Stability Criteria and Evaluation of Steering Maneuver in "Driver-Vehicle System", Transactions of the Japan Society of Mechanical Engineers, Series C,58-546(1992),418-424.

(10) Harada,M., and Yoshimoto,K., Parameter Estimation Algorithm of the Vehicle Dynamics by Genetic Algorithm, Proceedings of 6th International Symposium on Advanced Vehicle Control,(2002),349-354. 